\title{
Biodegradation of sulphosuccinate: direct desulphonation of a secondary sulphonate
}

\author{
Anthony Quick, ${ }^{1}$ Nicholas J. Russell, ${ }^{1}$ Stephen G. Hales ${ }^{2}$ and Graham F. \\ White $^{1}$
}

\author{
Author for correspondence: Graham F. White. Tel: +44222 874188. Fax: +44222 874116. e-mail: \\ whitegf1@cardiff.ac.uk
}

1 School of Molecular and
Medical Biosciences,
Biochemistry Unit,
University of Wales
Cardiff, PO Box 911,
Cardiff CF1 3US, UK
2 Unilever Research, Port
Sunlight Laboratory,
Bebington, Wirral,
Merseyside L63 3JW, UK

\begin{abstract}
The bacterial biodegradation of a secondary sulphonate, sulphosuccinate, has been shown to occur by direct desulphonation. A bacterium, designated Pseudomonas sp. BS1, was isolated from activated sewage sludge, for its capacity to grow on sulphosuccinate as the sole source of carbon and energy. Cultures grown on sulphosuccinate were able to convert this substrate to sulphite which was subsequently oxidized rapidly to sulphate. The sequence of desulphonation and carbon-chain catabolism of sulphosuccinate was determined from measurements of the kinetics of sulphite and ${ }^{14} \mathrm{CO}_{2}$ release from specifically radiolabelled sulpho[ $\left[1,4-{ }^{-14} \mathrm{C}\right]$ succinate and sulpho[2,3$\left.{ }^{14} \mathrm{C}\right]$ succinate, which were synthesized from the corresponding maleic anhydrides. When each radiolabelled compound was incubated separately with washed-cell suspensions of Pseudomonas BS1, sulphite was released before ${ }^{14} \mathrm{CO}_{2}$, as shown by chemical assay and radiorespirometry, respectively.

Differences in the kinetics and extent of ${ }^{14} \mathrm{CO}_{2}$ release from the 1,4- and 2,3labelled substrates were consistent with entry of the intact $C_{4}$ chain into the citric acid cycle. When carrier oxaloacetate was added to incubation mixtures containing resting-cell suspensions and radiolabelled sulphosuccinate, a radiolabelled metabolite with the same HPLC retention time as oxaloacetate accumulated. No radioactive metabolites accumulated when carrier oxaloacetate was replaced with succinate, fumarate or malate. Collectively, the data indicated co-production of sulphite and oxaloacetate from sulphosuccinate, which is interpreted in terms of an oxidative desulphonation mechanism.
\end{abstract}

Keywords: sulphonate, biodegradation, surfactant, desulphonation

\section{INTRODUCTION}

Dialkyl esters of sulphosuccinic acid [ROCO. $\mathrm{CH}_{2}$. $\mathrm{CH}\left(\mathrm{SO}_{3}^{-}\right) \mathrm{COOR}^{\prime}$; DASS; Fig. 1] constitute an interesting group of synthetic surfactants with commercial importance by virtue of their excellent wetting, foaming, emulsifying and dispersing properties (Linfield, 1976). Current applications include anti-fogging agents, inks, pesticide sprays, shampoos, cosmetics, dishwashing liquids and the textile industry. Production, use and waste-disposal of such widely-used compounds is likely to lead to their entry into the environment which in turn raises questions about their biodegradability.

Published studies on the biodegradation of DASS sur-

Abbreviation: DASS, dialkylsulphosuccinate. factants have been restricted to experiments with mixed microbial cultures. The primary biodegradation (i.e. the initial step which removes the surface-active properties) of DASS, measured using a range of assay methods, is virtually complete but takes from a few days up to 2-3 weeks, depending on the source of bacteria (e.g. sewage sludge or river-water) and the assay system (Swisher, 1987; Schoberl et al., 1988; Hales, 1993, and references therein). In contrast, ultimate (complete) biodegradation, measured by dissolved-organic-carbon (DOC) removal, $\mathrm{CO}_{2}$ production or release of sulphate, was incomplete, varying between $30 \%$ and $70 \%$ depending on the system used (Hales, 1993; Swisher, 1987). Hammerton (1956) showed that biodegradation was influenced by the nature of the alkyl chains and concluded that the ester link was not the point of bacterial attack. However, more recently Hales (1993), using hexyl/octyl sulpho $\left[{ }^{14} \mathrm{C}\right]$ succinate with 
<smiles>COC(=O)CC(C(=O)[O-])[S+](=O)[O-]</smiles>

Sulphosuccinate

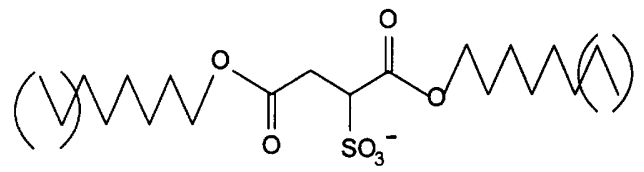

Dialkylsulphosuccinate

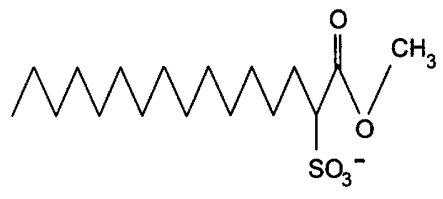

Fatty acid ester sulphonate

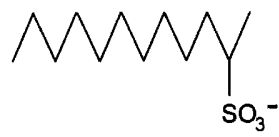

Secondary alkanesulphonate

Fig. 1. Structures of sulphosuccinate and some sulphonated surfactants.

mixed bacterial cultures from a pilot-scale sewage-treatment plant, showed that there were probably two alternative biodegradation pathways (depending on which alkyl chain was released first); he proposed that both pathways channel substrate via sulphosuccinate (Fig. 1) for ultimate biodegradation, and that desulphonation of DASS does not occur prior to dealkylation. Because succinate itself is readily assimilated by bacteria, it would appear that the removal of the sulphonate group from sulphosuccinate is critical for ultimate biodegradation to take place. A further reason for studying the biodegradation of sulphosuccinate is that similar small aliphatic molecules containing secondary sulphonate bonds are likely to be the intermediates of metabolism of related surfactants, such as fatty acid ester sulphonates (Steber \& Wierich, 1989; Masuda et al., 1993) and possibly from $\omega / \beta$-oxidation of secondary alkanesulphonates (see Fig. 1 for structures).

Long-chain primary aliphatic sulphonate surfactants with the $-\mathrm{SO}_{3}^{-}$moieties attached at terminal carbons of alkyl chains are known to be biodegraded by desulphonation via mono-oxygenation which introduces a hydroxyl group at the sulphonated carbon (Thysse \& Wanders, 1972, 1974). These authors also mentioned that dodecane 2-sulphonate was desulphonated to dodecan-2-one, but no experimental details were given. Moreover, there are abundant naturally occurring primary aliphatic sulphon- ates such as the plant sulpholipid 6-sulpho- $\alpha$-D-quinovopyranosyl-2,3-diacyl-D-glycerol (Harwood \& Russell, 1984) and taurine in animals (Schram \& Crokaert, 1957), and there is good evidence that these compounds undergo microbial biodegradation (Schram \& Crokaert, 1957; Martelli \& Benson, 1964; Martelli \& Souza, 1970; Shimamoto \& Berk, 1980; Uria-Nickelsen et al., 1993a, b). In comparison, secondary sulphonates of biological origin have yet to be reported. Therefore, it is important to establish whether there are micro-organisms capable of degrading them and by what means this is achieved.

This paper describes the metabolic route whereby a bacterial isolate, which is capable of growth on sulphosuccinate as the sole source of carbon and energy, accesses the carbon in this secondary sulphonate. We show that there is direct desulphonation of the growth substrate, without prior catabolism of the $\mathrm{C}_{4}$ chain.

\section{METHODS}

Materials. Dialkyl sulphosuccinate $\left(40: 60\right.$ mixture of $C_{6} / C_{8}$ alkyl chains, $89 \%$ pure) used for bacterial enrichments was synthesized at Unilever Research, Port Sunlight Laboratory (Bebington, Merseyside, UK). Di(ethylhexyl) sulphosuccinate for the production of sulphosuccinate, and Ellman's reagent [5,5'-dithiobis(2-nitrobenzoic acid)] were obtained from Sigma. $\left[2,3-{ }^{14} \mathrm{C}\right]$ Maleic anhydride (radiochemical purity $>95 \%$ and specific radioactivity $\left.50 \mathrm{GBq} \mathrm{mol}{ }^{-1}\right)$, and $\left[1,4^{14} \mathrm{C}\right]$ maleic anhydride (radiochemical purity $>98 \%$ and specific radioactivity $60 \mathrm{GBq} \mathrm{mol}^{-1}$ ) for synthesis of radiolabelled sulphosuccinate were obtained from Sigma. Radiolabelled standards for HPLC analysis were obtained as follows: $\left[1{ }^{14} \mathrm{C}\right]$ fumarate from ICN; $\left[\mathrm{U}-{ }^{14} \mathrm{C}\right]$ malate and $\left[1-{ }^{14} \mathrm{C}\right]$ acetate from Amersham International; and $\left[2,3-{ }^{14} \mathrm{C}\right]$ succinate from Sigma.

Hionic-fluor and Opti-fluor scintillation fluids were purchased from Canberra-Packard. Nutrient agar, Noble agar and yeast extract were obtained from Difco. The API 20B test kits used for the identification of environmental bacteria were obtained from API Laboratory Products. All other chemicals (AnalaR grade) were supplied by BDH-Merck.

Isolation of a sulphosuccinate-degrading bacterium. Enrichment cultures were established in a mineral salts medium containing $\left(\mathrm{g} \mathrm{l}^{-1}\right): \mathrm{K}_{2} \mathrm{HPO}_{4}, 7 ; \mathrm{KH}_{2} \mathrm{PO}_{4}, 3 ; \mathrm{NH}_{4} \mathrm{Cl}, 0 \cdot 5 ; \mathrm{NaCl}$, $0 \cdot 15 ; \mathrm{MgCl}_{2} \cdot 6 \mathrm{H}_{2} \mathrm{O}, 0.5$, and $1 \mathrm{ml}$ of a trace elements solution containing $20 \mathrm{mg} \mathrm{l}^{-1}$ each of $\mathrm{Na}_{2} \mathrm{~B}_{4} \mathrm{O}_{7}, \mathrm{CuSO}_{4} .5 \mathrm{H}_{2} \mathrm{O}$, $\mathrm{CoSO}_{4} \cdot 7 \mathrm{H}_{2} \mathrm{O}, \quad\left(\mathrm{NH}_{4}\right)_{6} \mathrm{Mo}_{7} \mathrm{O}_{24} \cdot 4 \mathrm{H}_{2} \mathrm{O}, \quad \mathrm{MnSO}_{4} \cdot \mathrm{H}_{2} \mathrm{O}$ and $\mathrm{ZnSO}_{4}$. In some early experiments the mineral medium also contained $\mathrm{Na}_{2} \mathrm{SO}_{4}\left(0 \cdot 15 \mathrm{~g} \mathrm{l}^{-1}\right)$. Enrichments were performed in baffled Erlenmeyer flasks $(250 \mathrm{ml})$ containing $50 \mathrm{ml}$ of the mineral salts medium supplemented with filter-sterilized (Millipore membrane filters, $0.2 \mu \mathrm{m}$ pore size) sulphosuccinate or DASS to give a final concentration of $0 \cdot 1 \%(\mathrm{w} / \mathrm{v})$. Flasks were inoculated with activated sewage sludge $(1 \%, \mathrm{v} / \mathrm{v})$ obtained from Coslech sewage works, South Glamorgan, Wales and shaken at 120 r.p.m. and $30^{\circ} \mathrm{C}$ in a rotary incubator. When growth was visible, samples were subcultured $(2 \%, v / v)$ into identical fresh medium. After three subculturings, samples $(0.1 \mathrm{ml})$ of the liquid cultures were plated on nutrient agar and incubated at $30^{\circ} \mathrm{C}$ for $48 \mathrm{~h}$ when individual colonies could be selected for further growth in liquid or on solid medium.

Growth of cultures and preparation of resting-cell suspensions. Cultures were grown to late-exponential phase 
$\left(\mathrm{OD}_{420}=1 \cdot 3-1 \cdot 4\right)$ in baffled Erlenmeyer flasks $(250 \mathrm{ml})$ containing $50 \mathrm{ml}$ minerals salts medium supplemented with sulphosuccinate $(1 \%, \mathrm{w} / \mathrm{v})$ and yeast extract $(0.005 \%, \mathrm{w} / \mathrm{v})$ and harvested by centrifugation at $4000 g_{\mathrm{av}}$ for $20 \mathrm{~min}$. The bacterial cell pellet was washed twice by resuspension in mineral salts solution $(50 \mathrm{ml})$ having the same composition as that of the growth medium, followed by recentrifugation as above and final resuspension in $5 \mathrm{ml}$ of the salts solution to give a bacterial cell density of approximately $20 \mathrm{mg}$ wet wt $\mathrm{ml}^{-1}$. For incubations with radiolabelled substrates, the cell suspensions $(10 \mathrm{ml})$ were placed in sterile $100 \mathrm{ml}$ Erlenmeyer flasks and shaken at 120 r.p.m. in a rotary incubator at $30^{\circ} \mathrm{C}$.

\section{Preparation of sulphosuccinate from dialkylsulphosuccinate.} Di(ethylhexyl) sulphosuccinate $(150 \mathrm{~g})$ was boiled under reflux in $1.510 .1 \mathrm{M} \mathrm{HCl}$ for $24 \mathrm{~h}$. The cooled mixture was extracted three times with light petroleum $\left(60-80^{\circ} \mathrm{C}\right.$ b.p. fraction) to remove liberated alcohol. The aqueous phase was taken to dryness in a rotary evaporator and the residue redissolved in $200 \mathrm{ml}$ distilled water and converted to the trisodium salt by addition of $0.2 \mathrm{M} \mathrm{NaOH}$ until the $\mathrm{pH}$ was 10 . The solution was evaporated and the resulting solid stirred in $200 \mathrm{ml}$ ethanol for $1 \mathrm{~h}$. The slurry was centrifuged at $3000 \boldsymbol{g}_{\mathrm{av}}$ for $20 \mathrm{~min}$ to separate the insoluble sulphosuccinate. The supernatant was discarded, the ethanol washing repeated and the final product dried at $60{ }^{\circ} \mathrm{C}$.

Infra-red spectra of the product compressed in $\mathrm{KBr}$ discs were obtained using a Perkin-Elmer 137 Infracord infra-red spectrometer. The spectra showed absorption bands at $1190-1250 \mathrm{~cm}^{-1}$ and $1060 \mathrm{~cm}^{-1}$ corresponding to vibrations in the sulphonate group, and carboxylate resonances at $1550-1610 \mathrm{~cm}^{-1}$ and $1700 \mathrm{~cm}^{-1}$. Minor bands at $3300 \mathrm{~cm}^{-1}$ were due to the presence of residual water in the dried sample.

To confirm the structure as sulphosuccinate, ${ }^{1} \mathrm{H}$-nuclear magnetic resonance spectroscopy of the chemically synthesized product dissolved in $\mathrm{D}_{2} \mathrm{O}$ was carried out using a Bruker WM 360 nuclear magnetic resonance spectrometer operating in the Fourier transform mode. A $180-\tau-90$ pulse sequence $(\tau \sim 3 \mathrm{~s})$ with a recycle time of $5 \mathrm{~s}$ was used to eliminate the solvent peak (HDO). Samples gave spectra that were characteristic of a compound having two geminal protons coupled to each other on a carbon atom that was attached to a chiral carbon atom carrying a single proton; no other protons were detected and the chemical-shift values were consistent with a compound having the general structure ${ }^{-} \mathrm{OOC}-\mathrm{CH}_{\mathrm{a}} \mathrm{H}_{\mathrm{b}}-\mathrm{CH}_{\mathrm{x}}\left(\mathrm{SO}_{3}^{-}\right) \mathrm{COO}^{-}$. The values of the coupling constants for the protons were $J_{\mathrm{ab}}=$ $13 \mathrm{~Hz}, J_{\mathrm{ax}}=10 \mathrm{~Hz}$ and $J_{\mathrm{bx}}=4 \mathrm{~Hz}$, which are typical of gemand vicinal-substituted protons. Elemental analyses of the synthesized sulphosuccinate were $\mathrm{C}=16.52 \%, \mathrm{H}=1.71 \%$, which were in close agreement with the theoretical values of $\mathrm{C}=17.02 \%$ and $\mathrm{H}=1.77 \%$ for the trisodium salt monohydrate.

Preparation of ${ }^{14} \mathrm{C}$-labelled sulphosuccinate. Sulpho[1,4$\left.{ }^{14} \mathrm{C}\right]$ succinate and sulpho $\left[2,3-{ }^{14} \mathrm{C}\right]$ succinate were prepared by converting the correspondingly radiolabelled maleic anhydrides first to the dioctyl esters, then adding sulphite at the double bond, and finally removing the octyl groups by hydrolysis. Carrier maleic anhydride $(0.18 \mathrm{~g}, 1.84 \mathrm{mmol})$ was dissolved in $10 \mathrm{ml}$ anhydrous toluene. The appropriate radiolabelled maleic anhydride ( $3.7 \mathrm{MBq}$, about $0.05 \mathrm{mmol}$ ) was added, followed by $0.71 \mathrm{ml}(6.5 \mathrm{mmol})$ anhydrous octanol and a few crystals of $p$ toluene sulphonic acid as catalyst. The mixture was heated under reflux for $4 \mathrm{~h}$, cooled and extracted sequentially once with $15 \mathrm{ml} \mathrm{NaOH}(30 \%, \mathrm{w} / \mathrm{v})$, twice with $15 \mathrm{ml}$ water and finally twice with $15 \mathrm{ml}$ saturated $\mathrm{NaCl}$. The organic phase was evaporated under reduced pressure to leave the di-octyl maleate as a yellow liquid (about $2 \mathrm{ml}$ ). The residue was dissolved in $2 \mathrm{ml}$ ethanol and sulphonation of the double bond was achieved by the addition of $1.8 \mathrm{ml}$ sodium metabisulphite $(40 \%, \mathrm{w} / \mathrm{v})$ and boiling under reflux for $6 \mathrm{~h}$. Excess inorganic salts were precipitated from the cooled mixture by the addition of $10 \mathrm{ml}$ ethanol and removed by centrifugation at $2000 \boldsymbol{g}_{\mathrm{av}}$ for $10 \mathrm{~min}$. The supernatant was taken to dryness to leave dioctyl sulphosuccinate as a white powder. The radiolabelled surfactant was converted to sulphosuccinate by hydrolysis in $5 \mathrm{ml} 0.2 \mathrm{M} \mathrm{HCl}$ under reflux for $24 \mathrm{~h}$. The cooled solution was extracted twice with $10 \mathrm{ml}$ light petroleum $\left(60-80^{\circ} \mathrm{C}\right.$ b.p. fraction) to remove octanol. Sulphosuccinate was recovered by rotary evaporation of the aqueous phase and converted to the sodium salt as described for unlabelled material. Final purification was achieved by preparative TLC $(20 \mathrm{~cm} \times 20 \mathrm{~cm} \times 2 \mathrm{~mm}$ layer, silica gel 60 , Merck) with propan-2-ol/water $(7: 3, \mathrm{v} / \mathrm{v})$ as the developing solvent.

Assay for sulphite. Sulphite was quantified by reaction with Ellman's reagent [5,5'-dithiobis(2-nitrobenzoic acid); $1 \mathrm{mg}(\mathrm{ml}$ $0 \cdot 1 \mathrm{M}$ phosphate buffer $)^{-1}, \mathrm{pH} 7 \cdot 0$ ] according to the method of Johnston et al. (1975). Samples $(1 \mathrm{ml})$ of incubations with radiolabelled substrates (see above) were removed at intervals, placed in Eppendorf tubes and centrifuged in a microcentrifuge. A portion $(0.25 \mathrm{ml})$ of the supernatant was removed and diluted to $1 \mathrm{ml}$ with distilled water. Ellman's reagent $(0.1 \mathrm{ml})$ was added, the solution mixed and incubated at room temperature for $2 \mathrm{~min}$ for colour development before measuring the absorbance at $415 \mathrm{~nm}$ using a LKB Novaspec spectrophotometer and a reagent blank. Sulphite reacts with the disulphide form of Ellman's reagent to give 5-thio 2-nitrobenzoate: the assay is sensitive, rapid and obeys Beer's law up to a concentration of $0 \cdot 1 \mathrm{mM}$. However, Ellman's reagent also gives a positive colour reaction with thiols. Therefore, control experiments were carried out routinely in which $10 \mathrm{ml} 50 \mathrm{mM}$ formaldehyde was added to the Ellman's reagent $(0.1 \mathrm{ml}$ as above) to remove the sulphite by formation of a formaldehyde sulphoxylate (Roy \& Trudinger, 1970); in such controls the residual absorbance would be due to thiols and can be used to correct the test values.

Radiorespirometry. The release of ${ }^{14} \mathrm{CO}_{2}$ during bacterial metabolism of radiolabelled substrates was quantified by radiorespirometry and liquid scintillation counting. The apparatus consisted of a series of glass scintillation vials each containing an open plastic mini-vial insert and sealed with a Teflon-coated rubber septum through which solutions couid be injected aseptically. The apparatus was sterilized by autoclaving and, shortly before use, $0.35 \mathrm{ml} 1 \mathrm{M} \mathrm{KOH}$ was added to the mini-vial to trap any ${ }^{14} \mathrm{CO}_{2}$ evolved. Washed bacterial suspension (1 ml, $20 \mathrm{mg}$ wet wt $\mathrm{ml}^{-1}$; see above) was rapidly premixed with substrate and added to the main compartment of the apparatus (i.e. inside the glass vial but outside the mini-vial insert) to start the incubation. The substrate was comprised of a mixture of non-radioactive and specifically radiolabelled sulphosuccinate (see above) adjusted so that the final concentration in the incubation mixture was $0.4 \mathrm{mM}$ at a specific radioactivity of $2 \cdot 5 \mathrm{kBq} \mathrm{mmol}^{-1}$ (equivalent to $1 \mathrm{kBq} \mathrm{ml}^{-1}$ ).

Since the objective was to measure the release of both sulphite and ${ }^{14} \mathrm{CO}_{2}$, the reaction could not be stopped by the addition of trichloroacetic acid (as commonly done in radiorespirometry) because such acidification interferes with the sulphite assay. Instead, the reaction was stopped by centrifuging aliquots $(0.4 \mathrm{ml})$ of the incubation mixture rapidly in an Eppendorf tube using a microcentrifuge. The radioactivity in a portion $(0.25 \mathrm{ml})$ 
of the supernatant was determined by liquid scintillation counting using a LKB Rackbeta liquid scintillation spectrometer with $5 \mathrm{ml}$ Opti-fluor as the scintillant. The efficiency of counting was determined using the external standard channelsratio facility on the scintillation counter, programmed using a series of control samples quenched with chloroform. Residual activity in the complete (i.e. uncentrifuged) incubation medium was determined by counting portions $(100 \mu \mathrm{l})$. Control experiments showed that the combined efficiency of $\mathrm{CO}_{2}$ trapping by the $\mathrm{KOH}$ and scintillation counting (after correction for quenching) was only reduced to $90 \%$ by omission of the acidification step.

To quantify the ${ }^{14} \mathrm{CO}_{2}$ trapped by the $\mathrm{KOH}$, the mini-vial insert was removed and the outside washed free of residual incubation mixture. Scintillation fluid ( $3.5 \mathrm{ml}$ Hionic-fluor) was added to the contents of the mini-vial, which was stoppered and the radioactivity in $\mathrm{K}_{2}^{14} \mathrm{CO}_{3}$ measured. The residual radioactivity in the incubation mixture was measured by counting a portion $(100 \mu \mathrm{l})$.

HPLC analysis for TCA intermediates. Incubations of washed bacterial suspensions were incubated with radiolabelled sulphosuccinate as described above for radiorespirometry. Samples $(100 \mu \mathrm{l})$ were transferred at timed intervals into screw-cap Eppendorf tubes and boiled for $5 \mathrm{~min}$ to release soluble metabolites from the bacteria. The tubes were centrifuged in a microfuge and the supernatant analysed by HPLC.

Separation of metabolites of sulphosuccinate was achieved by reverse-phase HPLC using a Spherisorb C8 column $(15 \mathrm{~cm} \times 4.6 \mathrm{~mm}$, particle size $3 \mu \mathrm{m}$, Jones Chromatography, Hengoed, Wales) with a Milton Roy CM4000 solvent delivery system. The system was driven by an Axxiom Chromatography 727 HPLC software package, version 3.67. Radiolabelled metabolites were detected using a Beckman 171 radioisotope detector with a flow-cell scintillation counter (flow-cell volume, $600 \mu \mathrm{l})$. Samples $(40 \mu \mathrm{l})$ were injected via a Rheodyne injection loop. The following authentic compounds were used as ${ }^{14} \mathrm{C}$ labelled standards for identification of metabolites: acetate, aspartate, malate, succinate and fumarate. In addition, unlabelled standards of cis-aconitate, citrate, oxaloacetate, pyruvate and glyoxylate, were eluted from the same chromatographic system and detected by UV absorbance at $210 \mathrm{~nm}$ in a Milton Roy 310 flow spectrometer.

\section{RESULTS}

\section{Isolation and growth of organism}

Attempted enrichments in mineral medium containing DASS and added sodium sulphate produced numerous isolates capable of growth on DASS, but none which could utilize sulphosuccinate as growth substrate. Synthesis of bacterial sulphatase enzymes acting on sulphate esters is often repressed by more readily assimilable sources of sulphur such as inorganic sulphate (Dodgson $e t$ al., 1982). Similar repression may regulate the biosynthesis of desulphonation systems. From a second series of enrichments in medium lacking added sulphate, a mixed culture was obtained, derived from activated sewage sludge, which showed rapid and substantial biodegradation of DASS. Because DASS was now also the sole source of sulphur as well as carbon, the vigour of the growth suggested that all of the molecule, including sulphosuccinate was undergoing biodegradation. The mixed culture was subcultured into minimal medium containing sulphosuccinate $(1 \%, \mathrm{w} / \mathrm{v}$, but lacking sulphate). After three transfers, the culture was plated on nutrient agar from which colonies were picked for a further round of three sub-culturings on minimal medium containing sulphosuccinate. The fastest-growing isolate was selected and was identified as a Pseudomonas sp., using the API 20B test kit. This isolate was designated Pseudomonas BS1. It grew slowly on sulphosuccinate minimal medium (doubling time, $130 \mathrm{~h}$ ) but much more rapidly (doubling time, $22 \mathrm{~h}$ ) when the medium was supplemented with $0.005 \%(\mathrm{w} / \mathrm{v})$ yeast extract (Fig. 2). The growth curve was biphasic, and a separate experiment in which sulphosuccinate was omitted showed that the initial faster growth phase corresponded to utilization of the yeast extract. Pseudomonas BS1 was tested for its ability to grow on DASS, fatty acid ester sulphonate, secondary alkane sulphonate, $C_{1}-C_{6}$ linear primary alkanesulphonates, sulphoacetic acid, benzene sulphonate and $p$ toluene sulphonate. Even when incubation periods were extended over several weeks, no growth was observed on any of these compounds, thus indicating the inability of these compounds to serve as sole source of carbon and energy for growth.

\section{Metabolic studies}

Resting-cell suspensions of Pseudomonas BS1 (10-times concentrated relative to the volume of the harvested culture) rapidly released sulphite from sulphosuccinate (Fig. 3). Conversion was complete within $25 \mathrm{~min}$, after

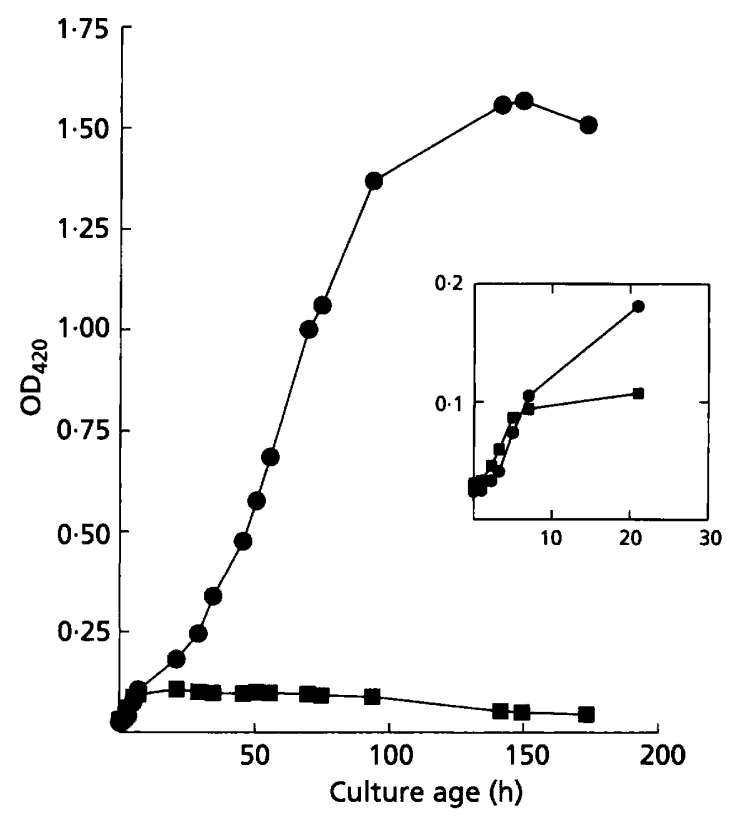

Fig. 2. Growth of Pseudomonas BS1 on sulphosuccinate $(0.1 \%$, w/v) supplemented with $0.005 \%(w / v)$ yeast extract $(O)$ and on $0.005 \%$ yeast extract alone $(\square)$. Growth was monitored by measurement of $O D_{420}$. 


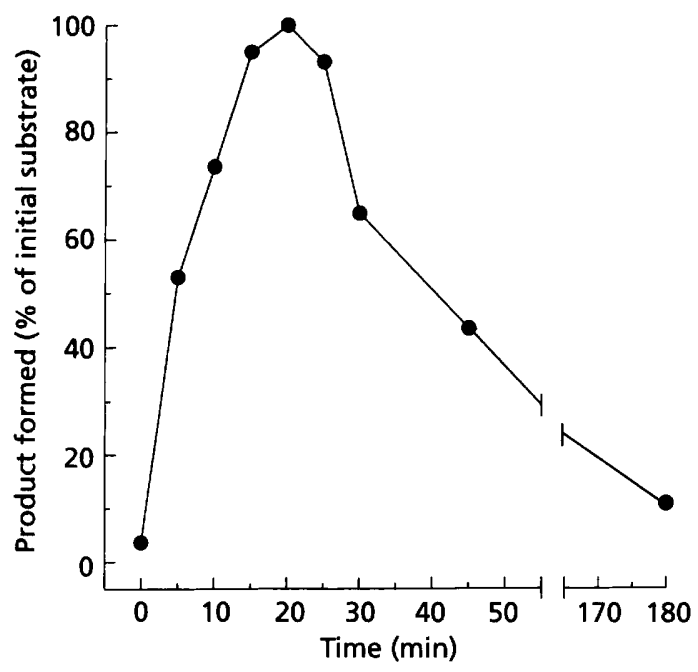

Fig. 3. Release of sulphite from sulphosuccinate by Pseudomonas BS1. Resting bacterial cell suspensions ( $20 \mathrm{mg}$ wet wt $\mathrm{ml}^{-1}$ ) of cultures grown on sulphosuccinate were incubated with $0.49 \mathrm{mM}$ sulphosuccinate, and the release of sulphite was quantified using the chemical assay of Johnston et al. (1975).

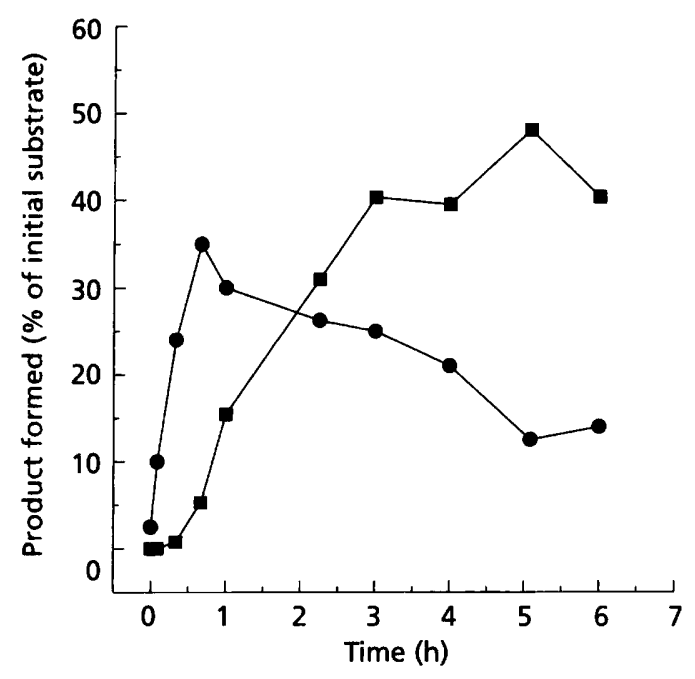

Fig. 4. Production of sulphite (O) and ${ }^{14} \mathrm{CO}_{2}(\square)$ from sulpho $\left[2,3-{ }^{14} \mathrm{C}\right]$ succinate by Pseudomonas BS1. Sulphite release was quantified chemically and ${ }^{14} \mathrm{CO}_{2}$ by radiorespirometry.

which the sulphite concentration rapidly decreased. Separate experiments indicated that disappearance of sulphite was coincident with formation of inorganic sulphate (data not shown).

When sulphite release and ${ }^{14} \mathrm{CO}_{2}$ production from sulpho[2,3-14 C]succinate were measured simultaneously, sulphite concentration again reached a maximum after $25 \mathrm{~min}$ and decreased thereafter (Fig. 4). In contrast, ${ }^{14} \mathrm{CO}_{2}$ release did not begin until sulphite release was well advanced, and reached its maximum value (about one-half of the total radiolabel present) in $3 \mathrm{~h}$.

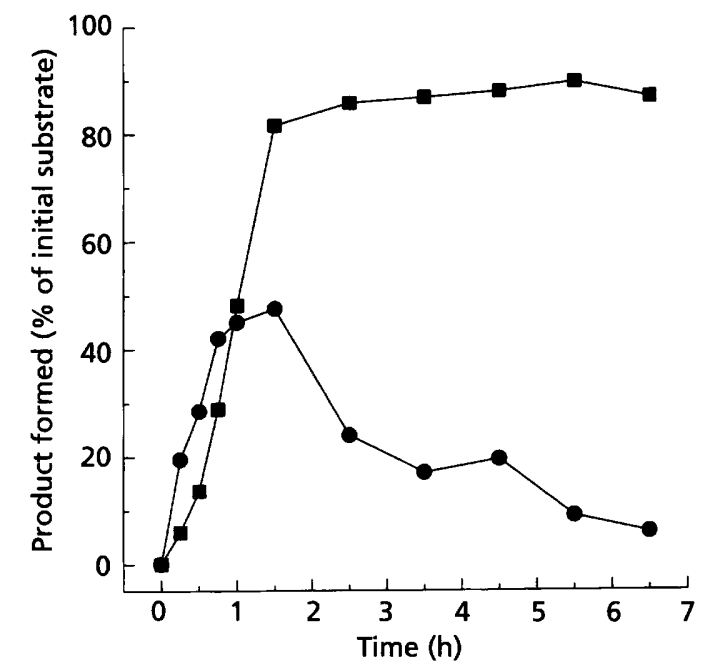

Fig. 5. Production of sulphite (O) and ${ }^{14} \mathrm{CO}_{2}$ (四) from sulpho $\left[1,4-{ }^{14} \mathrm{C}\right]$ succinate by Pseudomonas $\mathrm{BS} 1$. Sulphite release was quantified chemically and ${ }^{14} \mathrm{CO}_{2}$ by radiorespirometry.

In parallel experiments using sulpho $\left[1,4-{ }^{14} \mathrm{C}\right]$ succinate, sulphite release was again the initial event (Fig. 5) but ${ }^{14} \mathrm{CO}_{2}$ production differed in two respects from that observed with the 2,3-labelled substrate. Firstly, there was a much shorter lag period between sulphite liberation and ${ }^{14} \mathrm{CO}_{2}$ production and secondly, $90 \%$ of the total label added was oxidized to ${ }^{14} \mathrm{CO}_{2}$ (as compared to $40-50 \%$ for the 2,3- ${ }^{14} \mathrm{C}$-labelled compound). Because sulphite and ${ }^{14} \mathrm{CO}_{2}$ were produced rapidly and with an apparently small lag, a further experiment was performed to establish with certainty the presence of the lag. Increasing the sulphosuccinate concentration to $1 \mathrm{mM}\left(2.5 \mathrm{kBq} \mathrm{ml}^{-1}\right)$ slowed the overall process and confirmed the presence of a lag period (data not shown).

\section{HPLC analysis of biodegradation products}

When the boiled aqueous extracts of incubation mixtures of sulpho[1,4- $\left.{ }^{14} \mathrm{C}\right]$ succinate with resting-cell suspensions of Pseudomonas BS1 were analysed by radio-HPLC, there was a progressive disappearance of the starting radiolabelled compound (Fig. 6a). Similar results were obtained with sulpho $\left[2,3-{ }^{14} \mathrm{C}\right]$ succinate (data not shown). By $2 \cdot 5 \mathrm{~h}$ all of the starting material had been metabolized, and with the exception of a small amount of material with a retention time of $6.1 \mathrm{~min}$, there were no major accumulations of metabolic breakdown products. Separate additions of the citric acid cycle $\mathrm{C}_{4}$ intermediates, succinate, malate or fumarate, as unlabelled carriers, slowed the rate of biodegradation of radiolabelled sulphosuccinate, but did not cause the accumulation of any radiolabelled metabolites. In contrast, the addition of $3 \mathrm{mM}$ carrier oxaloacetate resulted in significant accumulation of the compound with a retention time of $6.1 \mathrm{~min}$ (Fig. 6b). This retention time was the same as that of standard oxaloacetate; it was also close to malate $(5.8 \mathrm{~min})$ and acetate $(6.0 \mathrm{~min})$, but not aspartate $(3.0 \mathrm{~min})$, succinate $(10.5 \mathrm{~min})$ and fumarate $(11.6 \mathrm{~min})$. 


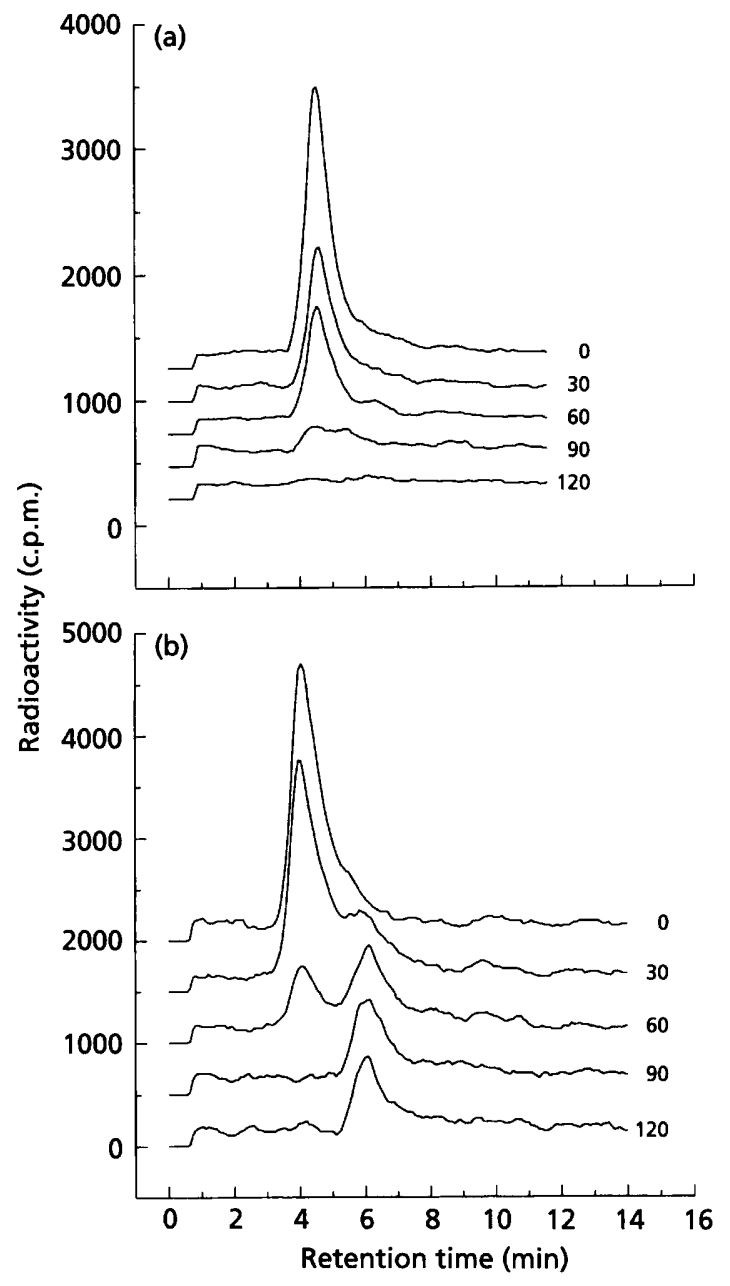

Fig. 6. HPLC analysis of the biodegradation of sulpho[1,4$\left.{ }^{14} \mathrm{C}\right]$ succinate by resting cell suspensions of Pseudomonas BS1 in (a) the absence or (b) the presence of excess unlabelled oxaloacetate $(3 \mathrm{mM})$. Each trace is labelled with the time (min) at which the sample was taken.

\section{DISCUSSION}

There are numerous reports of the desulphonation of aromatic and primary aliphatic sulphonates (Thysse \& Wanders, 1974; Shimamoto \& Berk, 1980; Cain, 1987; Swisher, 1987; Cook \& Leisinger, 1991; Uria-Nickelsen et al., 1993a, b). In comparison, understanding of the biodegradative pathways of secondary sulphonates is meagre and this paper presents for the first time a direct demonstration of the desulphonation of a secondary sulphonate. Earlier work (Steber \& Wierich, 1989) had shown that mixed bacterial cultures degraded $\alpha$-sulphofatty acid $\left(\mathrm{C}_{16}\right)$ methyl ester via $\omega / \beta$-oxidation to produce short-chain sulphonated dicarboxylic acids which have structures similar to that of sulphosuccinate. Although these intermediates were found to undergo ultimate biodegradation, the nature and timing of the desulphonation step was not established in those experiments. Thysse \& Wanders (1974), in their study of primary aliphatic sulphonate biodegradation, mention that dodecane 2-sulphonate underwent desulphonation to dodecan-2-one, but experimental details were not provided.

The present demonstration of the sequential liberation of sulphite then ${ }^{14} \mathrm{CO}_{2}$ from either 2,3- or 1,4-labelled sulphosuccinates (Figs 4 and 5) provides clear evidence that desulphonation precedes disruption of the $\mathrm{C}_{4}$ chain. Thus, the carbon chain of the sulphosuccinate remains intact during desulphonation which in turn means that sulphite is removed from a secondary carbon atom.

The sulphite released was converted rapidly to sulphate, and the speed of this oxidation is believed to be the cause of considerable inter-experimental variability in the maximum percentage of sulphite released from both the specifically radiolabelled sulphosuccinates. Sulphite oxidation was presumed to be due to the action of sulphite oxidase which has been detected in a number of other micro-organisms (Cohen \& Fridovich, 1971; Siegel, 1975); spontaneous oxidation of sulphite in air can also occur (McCord \& Fridovich, 1969). Despite the rapid appearance of sulphate, there was no doubt that the primary product of desulphonation was sulphite. This is consistent with initial steps in the desulphonation of arylsulphonates and primary aliphatic sulphonates (White \& Russell, 1993).

Biodegradation of sulpho $\left[{ }^{14} \mathrm{C}\right]$ succinate was accompanied by transient formation of small amounts of a radiolabelled metabolite (Fig. 6a, retention time $6.1 \mathrm{~min}$ ), the concentration of which was markedly increased by the presence of unlabelled oxaloacetate during biodegradation (Fig. 6b). The possible identities of this metabolite deduced from HPLC analysis were oxaloacetate $(6.1 \mathrm{~min})$, acetate $(6.0 \mathrm{~min})$ or malate $(5.8 \mathrm{~min})$. Acetate can be eliminated on theoretical grounds, since a mechanism for desulphonation which entrains simultaneous $\mathrm{C}-\mathrm{C}$ bond cleavage to acetate is difficult to envisage. An oxidative mechanism for the desulphonation would give oxaloacetate, whereas hydrolysis would be required to give malate. The latter seems less likely, in view of the stability of the C-S bond to hydrolysis (Wagner \& Reid, 1931) and the fact that oxidation is required to metabolize primary alkane sulphonates (White \& Russell, 1993). Moreover, under anaerobic conditions, dialkylsulphosuccinate undergoes hydrolytic removal of alkyl chains but no desulphonation (Hales, 1993), indicating that the latter is not a hydrolytic process. Thus, oxaloacetate seems to be the most likely identity of the ${ }^{14} \mathrm{C}$-labelled metabolite, and this proposition is supported by the experimental evidence. Firstly, the retention time of oxaloacetate, amongst those likely products, was the one which matched most closely that of the radioactive metabolite. Secondly, there was enhanced accumulation of the metabolite only in the presence of carrier oxaloacetate, but not with carrier malate, succinate or fumarate.

The formation of oxaloacetate from sulphosuccinate provides an explanation for the kinetics and extent of production of ${ }^{14} \mathrm{CO}_{2}$ (Figs 4 and 5). When the substrate was 1,4-labelled, ${ }^{14} \mathrm{CO}_{2}$ production was fast and extensive (approaching $90 \%$, see Fig. 5). This is consistent with the 
<smiles>O=C(O)CC(C(=O)[O-])C(=O)[O-]</smiles><smiles>CC(C)(CO)CO</smiles><smiles>[13CH3][C@]([14CH3])(CC(=O)O)C(=O)O</smiles><smiles>O=C(O)CC(=O)C(=O)O</smiles>
$\mathrm{SO}_{3}^{2-}$

Fig. 7. Proposed reaction mechanism for the desulphonation of sulphosuccinate.

well-known transformations of the citric acid cycle in which the citrate synthesized is 'biologically' asymmetrical: the $\mathrm{C}_{4}$ of oxaloacetate becomes the $\mathrm{C}_{1}$ carboxyl of isocitrate, and the $\mathrm{C}_{1}$ of oxaloacetate becomes the carboxyl attached at $\mathrm{C}_{3}$ of isocitrate. These two carboxyls are lost sequentially in the conversion of isocitrate $\rightarrow 2$-oxoglutarate $\rightarrow$ succinate. Thus, the succinate produced from $\left[1,4-{ }^{14} \mathrm{C}\right]$ oxaloacetate in the first round of the citric acid cycle is unlabelled and all radioactivity has been converted to ${ }^{14} \mathrm{CO}_{2}$.

In comparison, when the substrate was sulpho[2,3${ }^{14} \mathrm{C}$ ]succinate a different pattern of ${ }^{14} \mathrm{CO}_{2}$ production occurred (Fig. 4), which can also be explained by the known metabolic conversions of oxaloacetate via the citric acid cycle. Conversion of sulpho[2,3- $\left.{ }^{14} \mathrm{C}\right]$ succinate to $\left[2,3-{ }^{14} \mathrm{C}\right]$ oxaloacetate would lead to ${ }^{14} \mathrm{C}$ incorporation at the $\mathrm{C}_{2}$ and $\mathrm{C}_{3}$ positions of 2-oxoglutarate and thence into $C_{1}$ and $C_{2}$ of succinate. Thus, no ${ }^{14} \mathrm{CO}_{2}$ would be released in the first round of the citric acid cycle, in keeping with the distinct 15-20 min lag observed for this specifically radiolabelled sulphosuccinate (Fig. 4). Moreover, the succinate molecule is symmetrical and leads effectively to the formation of $\left[\mathrm{U}^{14} \mathrm{C}\right]$ oxaloacetate after the first round of the citric acid cycle. Therefore, in the second and subsequent rounds of oxidation by the citric acid cycle, only that part of the label at the $\mathrm{C}_{1}$ and $\mathrm{C}_{4}$ positions is converted to ${ }^{14} \mathrm{CO}_{2}$. In addition, repeated passage of radiolabel through metabolic intermediates such as 2-oxoglutarate and oxaloacetate during successive rounds of the cycle allows radiolabel to be diverted away from ${ }^{14} \mathrm{CO}_{2}$ production and into biomass. This accounts for the lower conversion of radiolabel to ${ }^{14} \mathrm{CO}_{2}$ from 2,3labelled sulphosuccinate compared with the 1,4-labelled substrate.

The formation of sulphite and oxaloacetate as initial products of sulphosuccinate metabolism is consistent with an oxidative mechanism (Fig. 7). In this mechanism, substrate undergoes oxidation at $\mathrm{C}_{2}$ to yield 2-sulphomalate. The $\mathrm{HO}-\mathrm{C}-\mathrm{SO}_{3}^{-}$structure is equivalent to the sulphite adduct of a carbonyl group, which can undergo spontaneous reformation of the carbonyl with elimination of sulphite. This mechanism is parallel to that proposed for desulphonation of primary aliphatic sulphonates (Thysse \& Wanders, 1972, 1974; Kelly \& Smith, 1990; Baker $e$ t al., 1991) except that the carbonyl forms an $\alpha$-keto acid, rather than an aldehyde. Masuda et al. (1993) have proposed that the biodegradation of methyl $\alpha$-sulphosuccinate derived from $\alpha$-sulphotetradecanoic acid methyl ester in mixed cultures from activated sewage sludge, yields oxaloacetate and sulphate. However, this conclusion was based solely on the late release of sulphate during surfactant biodegradation and the tentative identification of methyl $\alpha$-sulphosuccinate as an intermediate. The authors did not present any evidence that identified the $\mathrm{C}_{4}$ desulphonation product as oxaloacetate, nor did they consider the possibility of formation of sulphite as an intermediate, nor indicate any mechanism for the oxidative cleavage proposed.

The oxidative mechanism in Fig. 7 is distinct from that proposed for bacterial metabolism of sulphoacetaldehyde, which is mediated by a thiamine pyrophosphate-dependent sulphoacetaldehyde sulpho-lyase (Kondo \& Ishimoto, 1974, 1975) to produce sulphite and acetate. The latter mechanism involves covalent bonding between TPP and the aldehydic group of the substrate, a mechanism which is untenable for the catabolism of sulphosuccinate which lacks an aldehydic functional group. The mechanism proposed here for sulphosuccinate biodegradation is also distinct from that suggested for bacterial desulphonation of sulphoacetate (Martelli \& Souza, 1970) which involves a 'double' oxidation of both carbon and sulphur moieties to yield glycollate and sulphate.

\section{ACKNOWLEDGEMENTS}

We thank the Science and Engineering Research Council for a CASE Studentship (A.Q.), and Dr M. J. Hewlins, School of Chemistry, University of Wales Cardiff, for carrying out the NMR analysis.

\section{REFERENCES}

Baker, S. C., Kelly, D. P. \& Murrell, J. C. (1991). Microbial degradation of methanesulphonic acid: a missing link in the biogeochemical sulphur cycle. Nature 350, 627.

Cain, R. B. (1987). Biodegradation of anionic surfactants. Biochem Soc Trans 15, 7S-22S.

Cohen, H. J. \& Fridovich, T. (1971). Hepatic sulfite oxidase. Purification and properties. J Biol Chem 246, 359-366. 
Cook, A. M. \& Leisinger, T. (1991). Desulfonation of aromatic compounds. In Proceedings of the International Symposium on Environmental Biotechnology, part 1, pp. 115-122. Edited by $\mathrm{H}$. Verachtert \& W. Verstraete. Antwerp: Royal Flemish Society of Engineers.

Dodgson, K. S., White, G. F. \& Fitzgerald, J. W. (1982). Sulfatases of Microbial Origin. Boca Raton: CRC Press.

Hales, S. G. (1993). Biodegradation of the anionic surfactant dialkyl sulphosuccinate. Environ Chem Toxicol 12, 1821-1828.

Hammerton, C. (1956). Synthetic detergents and water supplies. Il. Chemical constitution of anionic surface active compounds and their susceptibility to biochemical oxidation. Proc Soc Water Treat Exam 5, 160-174.

Harwood, J. L. \& Russell, N. J. (1984). Lipids in Plants and Microbes. London: George Allen and Unwin.

Johnston, J. B., Murray, R. \& Cain, R. B. (1975). Microbial metabolism of aryl-sulfonates. A reassessment of colorimetric methods for the determination of sulfite and their use in measuring desulfonation of aryl- and alkylbenzenesulfonates. Antonie Leeuwenboek 41, 493-511.

Kelly, D. P. \& Smith, N. A. (1990). Organic sulphur compounds irı the environment. Biochemistry, microbiology and ecological aspects. Adv Microb Ecol 11, 345-385.

Kondo, H. \& Ishimoto, M. (1974). Requirement for thiaminc: pyrophosphate and magnesium for sulfoacetaldehyde sulfo-lyase: activity. $J$ Biochem 76, 229-231.

Kondo, H. \& Ishimoto, M. (1975). Purification and properties of sulfoacetaldehyde sulfo-lyase, a thiamine pyrophosphate-dependent enzyme forming sulfite and acetate. $J$ Biocbem 78, 317-325.

Linfield, W. M. (1976). Sulfopolycarboxylic acid derivatives. In Anionic Surfactants. Surfactant Science Series vol. 7, part II, pp. 405-443. Edited by W. M. Linfield. New York: Marcel Dekker.

McCord, J. M. \& Fridovich, T. (1969). The utility of superoxide dismutase in studying free radical reactions. I. Radicals generated by the interaction of sulfite, dimethylsulfoxide and oxygen. $J$ Biol Chem 244, 6056-6063.

Martelli, H. L. \& Benson, A. A. (1964). Sulfocarbohydrate metabolism. I. Bacterial production and utilization of sulfoacetate. Biochim Biophys Acta 93, 169-171.

Martelli, H. L. \& Souza, S. M. (1970). Biochemistry of sulfonic compounds. III. Formation of a two-carbon compound during the oxidation of sulfoacetate by a pseudomonas strain. Biochim Biophys Acta 208, 110-115.
Masuda, M., Odake, H., Miura, K., Ito, K., Yamada, K. \& Oba, K. (1993). Biodegradation of 2 -sulfonatofatty acid methyl ester. $(\alpha-$ SFMe). II. Biodegradation pathways of $\alpha$-SFMe. J Jpn Oil Chem Soc 42, 905-909.

Roy, A. B. \& Trudinger, P. A. (1970). The Biochemistry of Inorganic Sulphur Compounds. London: Cambridge University Press.

Schoberl, P., Bock, K. J. \& Huber, L. (1988). Okologisch relevante Daten von Tensiden in Wasch- und Reinigungsmitteln. Tenside Surf Deterg 25, 86-98.

Schram, E. \& Crokaert, R. (1957). Etude du metabolisme de la taurine chez le rat. Formation de sulfate. Biocbim Biopbys Acta 26, 300-308.

Shimamoto, G. \& Berk, R. S. (1980). Taurine catabolism. II. Biochemical and genetic evidence for sulfoacetaldehyde sulfolyase involvement. Biochim Biophys Acta 632, 121-130.

Siegel, L. (1975). Biochemistry of the sulfur cycle. In Metabolism of Sulfur Compounds, pp. 217-286. Edited by D. M. Greenberg. New York: Academic Press.

Steber, J. \& Wierich, P. (1989). The environmental fate of fatty acid a-sulfomethyl esters. Tenside Surf Deterg 26, 406-411.

Swisher, R. D. (1987). Surfactant Biodegradation. Surfactant Science Series, vol. 18. New York: Marcel Dekker.

Thysse, G. J. E. \& Wanders, T. H. (1972). Degradation of $n$-alkane1-sulfonates by Pseudomonas. Antonie Leeuwenboek 38, 53-63.

Thysse, G. J. E. \& Wanders, T. H. (1974). Initial steps in the degradation of $n$-alkane-1-sulfonates by Pseudomonas. Antonie Leeuwenboek 40, 25-37.

Uria-Nickelsen, M. R., Leadbetter, E. R. \& Godchaux, W. (1993a). Sulphonate utilization by enteric bacteria. J Gen Microbiol 139, 203-208.

Uria-Nickelsen, M. R., Leadbetter, E. R. \& Godchaux, W. (1993b). Sulphonate-sulfur assimilation by yeasts resembles that of bacteria. FEMS Microbiol Lett 114, 73-78.

Wagner, F. C. \& Reid, E. E. (1931). The stability of the carbonsulphur bond in some aliphatic sulphonic acids. J Am Chem Soc 53, 3407-3413.

White, G. F. \& Russell, N. J. (1993). Biodegradation of anionic surfactants and related compounds. In Biochemistry of Microbial Degradation, pp. 143-177. Edited by C. Ratledge. Dordrecht: Kluwer.

Received 27 May 1994; accepted 21 July 1994. 